\title{
Clinical Comparison of Transoral Removal with Sublingual Gland Preservation versus without Sublingual Gland Preservation versus Submandibular Gland Resection for Proximal Duct Stone of Submandibular Gland: Prospective Study
}

\author{
Geonwoo Kim, Jaemoon Sung, Hwikyeong Jung, Jaesoon Kim, Minwoo Park, and Keehwan Kwon (D) \\ Department of Otorhinolaryngology-Head and Neck Surgery, Gangdong Sacred Heart Hospital, Hallym University College of Medicine, \\ Seoul, Korea
}

근위부 악하선 타석 제거수술 결과의 전향적 비교: 설하선 보존 경구강 타석 제거술, 설하선 절제 경구강 타석 제거술, 악하선 제거술

김건우 - 성재문 - 정휘경 - 김재순 - 박민우 - 권기환

한림대학교 의과대학 강동성심병원 이비인후과학교실

Received September 9, 2019

Revised September 30, 2019

Accepted October 4, 2019

Address for correspondence

Keehwan Kwon, MD

Department of Otorhinolaryngology-

Head and Neck Surgery,

Gangdong Sacred Heart Hospital,

Hallym University

College of Medicine,

150 Seongan-ro, Gangdong-gu,

Seoul 05355, Korea

Tel $+82-2-2224-2279$

Fax $+82-2-482-2279$

E-mail entkhkwon@kdh.or.kr
Background and Objectives Proximal submandibular stone is not a rare disease. The aim of this study is to evaluate the surgical outcomes of 3 different ways to treat proximal submandibular stone: intraoral removal of stone (IORS) with sublingual gland (SLG) resection, IORS without SLG resection and submandibular gland (SMG) resection.

Subjects and Method We prospectively reviewed the surgical outcomes of IORS with SLG resection group (22 patients), IORS without SLG resection group (35 patients) and SMG resection group (22 patients). To evaluate the surgical outcomes, we analyzed the location and size of stones, mean operation time, mean hospital stay, mean postoperative degree of pain based on a visual analog scale (0-10), and incidence of complications.

Results There were no significant differences between the mean diameter of stones and length from the hilum to stones. The mean operation time was shorter in the IORS without SLG resection group than that in IORS without SLG resection group, and was significantly shorter than that of the SMG resection group. The mean hospital stay of the IORS without SLG resection group was also shorter than that of IORS with SLG resection group, and was significantly shorter than the SMG resection group. IORS without SLG resection group felt less pain than IORS with SLG resection group and SMG resection group. Four patients who underwent IORS without SLG resection experienced transient and mild SMG swelling, and mild paresthesia was noted on the same side. All patients recovered within 3 months. Intraoral removal of proximal SMG stones exhibited several advantages over SMG resection in terms of hospital stay, mean operation, time and postoperative pain.

Conclusion Based on our results, we suggest that IORS without SLG resection be selected as the primary procedure for the removal of proximal submandibular stones rather than SMG resection. Korean J Otorhinolaryngol-Head Neck Surg 2021;64(2):93-7

Key Words Salivary gland calculi $\cdot$ Sublingual gland $\cdot$ Submandibular gland.

This is an Open Access article distributed under the terms of the Creative Commons Attribution Non-Commercial License (https://creativecommons.org/licenses/by-nc/4.0) which permits unrestricted non-commercial use, distribution, and reproduction in any medium, provided the original work is properly cited. 


\section{서 론}

폐쇄성 타액선염은 흔한 질환이며, 양성 타액선 질환의 절 반 정도를 차지한다.1) 폐쇄성 타액선염의 가장 흔한 임상 증상 은 식후에 발생하는 동통, 반복적인 부종으로, 반복적인 2차 감염은 타액선의 위축 및 타액선관의 협착 등의 영구적인 구 조적 손상을 초래할 수 있다. ${ }^{2}$ 타석증은 폐쇄성 타액선염의 가장 흔한 원인이며, 연간 발생률은 1/30000 1/10000로 보 고되어 있고, 주 침샘 중 악하선에서 80 90\%, 이하선에서 $5 \sim 10 \%$, 설하선에서 $1 \%$ 이내로 발병하는 것으로 알려져 있 다. ${ }^{3)}$ 악하선에서 주로 타석이 발생하는 이유는 악하선 타액 선관이 타 침샘관보다 길이가 길고, 배출구로 향할수록 상승 하는 침샘 경로 등의 해부학적 구조와 다른 타액과는 달리 칼슘과 인의 함량이 높고, 진한 점도 등으로 인한 여러 가지 생화학적 요인이 영향을 미치는 것으로 알려져 있다. ${ }^{4)}$ 타석이 장기간 방치될 경우에는 타액선 및 타액선관에 영구적인 구 조적 손상과 타액선의 감염을 초래할 수 있는 것으로 알려져 있다. 반면 타석 제거를 통해 타액선의 기능이 충분히 회복된 다는 연구 결과가 많이 나와 있다. ${ }^{5)}$ 악하선 타석의 약 $40 \%$ 가 량이 악하선관 원위부에서 발생하며, $10 \%$ 가량이 근위부에서 발생한다. ${ }^{6.7)}$ 기존의 타석 제거는 타석의 위치, 크기, 촉진 여 부에 따라 근위부인 경우에는 구강 내 접근법을 통한 타석 제거술이, 원위부이거나 악하선 내에 타석이 위치한 경우에 는 악하선 절제가 주로 사용되었다. 하지만 악하선 절제술은 얼굴신경, 설신경, 설하신경 손상, Frey 증후군, 미용적 문제 등으로 최근에는 타액선을 보존하는 최소 침습적인 치료법이 사용되고 있으며, 최소 침습적인 치료법으로는 침샘내시경, 충격파 쇄석술, 경구강 타석 제거술 등이 있다.8) 근위부 악하 선 타석은 타석의 위치가 악하선에 가까워 과거에는 악하선 을 절제하는 방법을 사용하였으나, 최근에는 경구강 타석 제 거술을 주로 사용하고 있으며, 설하선 절제 경구강 타석 제거 술과 악하선 절제술의 수술 결과를 비교한 보고에 따르면 두 그룹 간에 재원 일수, 평균 수술 소요 시간, 술 후 통증 등에 있어서 통계적으로 유의하게 설하선 절제 경구강 타석 제거 술이 양호한 수술 결과를 보여 주었다.) 이에 본 연구에서는 근위부 악하선 타석 환자의 치료에 있어서 설하선을 보존하 는 경구강 타석 제거술을 설하선 절제 경구강 타석 제거술과 악하선 절제술의 수술 결과와 비교 분석하여 설하선 보존 경 구강 타석 제거술의 치료 효과를 보고하고자 하였다.

\section{대상 및 방법}

2012 2016년까지 근위부 악하선관 타석증으로 설하선 보
존 경구강 타석 제거술을 시행한 35 명의 환자를 대상으로 전 향적으로 연구를 진행하였다(IRB No. 2020-01-006). 설하 선을 보존하는 경구강 타석 제거술을 설하선 절제 경구강 타 석 제거술과 악하선 절제술의 수술 결과와 비교하기 위해서 기존에 본원에서 보고된 근위부 악하선관 타석 환자 연구 결 과 ${ }^{9)}$ 중 설하선 절제 경구강 타석 제거술(22명)과 악하선 절 제술(22명)의 수술 결과와 비교 분석하였다(Table 1).

근위부 악하선관 타석의 진단은 초음파, 경부 단층촬영을 이용하였고, 첫 번째 대구치 후방에 위치하는 경우로 정의하 였다. 본 연구에는 타석 제거술이 처음인 환자와 정상 설신경 기능을 가진 환자들만 포함되었으며 이전의 연구를 포함한 모 든 수술은 한 명(KH Kwon)의 두경부외과의가 시행하였다. ${ }^{9}$

설하선 보존 경구강 타석 제거술의 수술 방법은 다음과 같 이 시행하였다. 모든 환자들은 전신마취하에서 수술을 시행 하였으며, 환자의 입을 Denhardt mouth gag으로 벌리고 병 변 쪽의 타액선과 구강을 노출시킨 후, 혀를 병변의 반대편으 로 당긴 후 right angle retractor(Langenback)로 협부를 당 겨 수술 시야를 확보하였다. 악하선 부근에 압력을 가하면서, 구강 내로 악하선관 부위를 촉진하여 타석의 위치를 추정하 였으며, 동측 악하선관 개구부에서 타석 추정 위치(악하선관 근위부)를 잇는 선의 $1 / 2$ 지점과 설하선의 내측 가장자리(설 하선의 소개구부들이 이루는 선 내측 4 5 mm)가 만나는 부 위에서 시작하여 종방향으로 2 3 cm를 절개하였다. 모스키토 (mosquito) 겸자, 테나토미(tenotomy) 가위를 이용하여 절개 부위를 박리하면서 설하선과 소개구부들을 측방으로 보존한 후 악하선관 및 설신경을 확인하여 보조 술자가 악하선 부근 에 압력을 가한 상태에서 right angle retractor(Langenback) 로 수술 시야를 확보하며 악하선관을 따라 근위부로 박리를 지속하였다. 설신경 또한 측방으로 보존하며 악하선관의 근 위부, 입구부까지 시야가 확보되고, 접근이 가능하며 양손 촉 지를 통해 타석의 위치를 확인한 후 악하선관에 절개를 가하 여 타석을 손상 없이 제거하였다. 타석을 제거한 후에는 경부 악하선 부위에서 손가락으로 압력을 반복적으로 가하여, 저 류되어 있는 점도가 높은 타액을 제거하거나 다발성 타석인 경우에는 남아 있는 타석을 제거하였다. 악하선관 및 수술 부 위 세척 시행 후 악하선관 절개 부위 봉합이나 악하선 관성 형술은 시행하지 않고 점막 절개 부위 봉합 시행 후 수술을 종료하였다(Figs. 1 and 2).

설하선 절제 경구강 타석 제거술은 과거의 보고된 방식과 같이 시행하였으며,") 설하선을 설신경을 보존하면서 악하선 관과 분리하여 절제한 후에 타석을 제거하는 방식으로 시행 하였다. 악하선 절제술은 경부 절개를 통한 전통적인 방식으 로 시행하였다. 


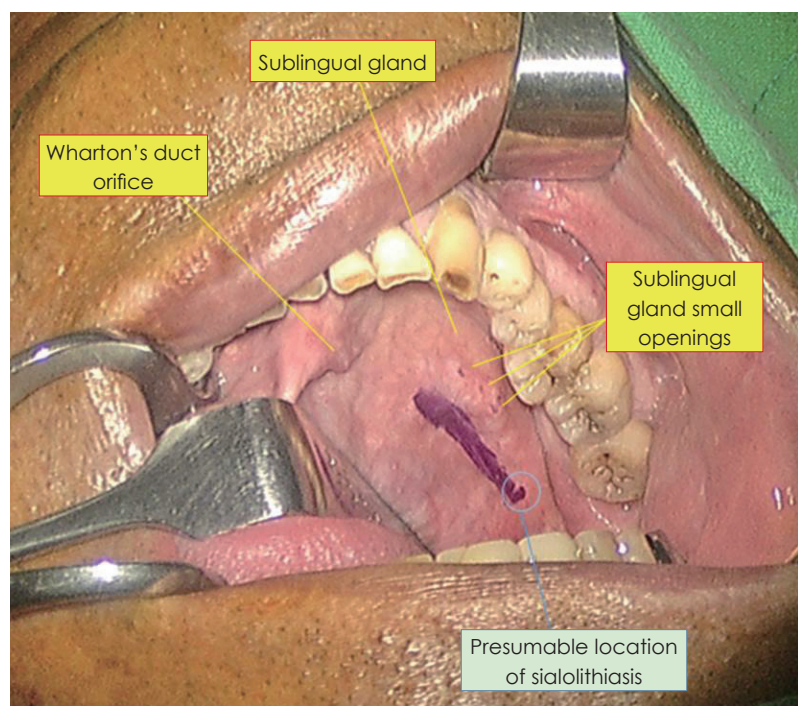

Fig. 1. Designing incision line. Operation site exposure with Denhardt mouth gag and tongue retracted contralaterally with right angle retractors (Langenback). $2-3 \mathrm{~cm}$ incision line from midpoint (between the Wharton's duct opening and obstructed location) to most medial side of sublingual gland.

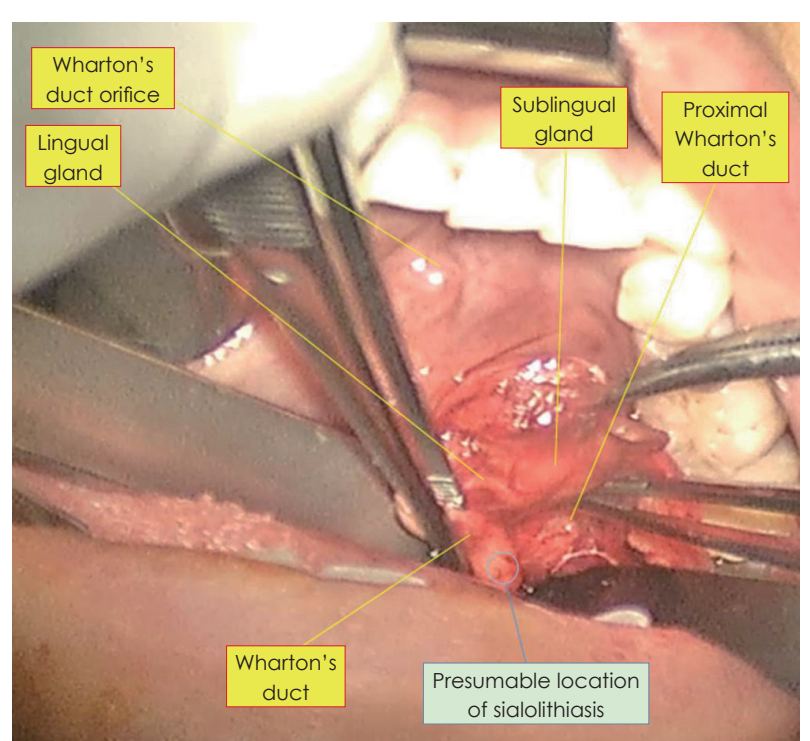

Fig. 2. Exposure of proximal submandibular duct. Dissecting along submandibular duct with mosquito forceps and retracting (and preserving) small duct openings, sublingual gland, and lingual nerve with right angle retractor (Langenback).

설하선 보존 경구강 타석 제거술군, 설하선 절제 경구강 타 석 제거술군, 악하선 절제술군의 수술 결과를 타석의 위치, 타석의 크기, 평균 수술 소요 시간, 재원 일수, visual analog scale(VAS; 0 10)로 표현한 통증, 수술 관련 합병증(구강 건 조증, 상처 감염, 감각 이상 혹은 소실, 설신경 기능 변화, meal-time 증후군, 타액선염 발생 여부) 등의 항목들을 조 사하였다(Table 2). 각 수술군 간의 수술 결과 비교를 위해 각각의 자료는 analysis of variance를 이용하여 통계 분석
하였다. 자료 분석을 위한 통계 처리는 IBM SPSS software (version 20, IBM Corp., Armonk, NY, USA)를 이용하였 고, $p$ value가 0.05 미만인 경우를 통계학적으로 유의한 것으 로 간주하였다.

\section{결 과}

타석의 평균 지름은 설하선 보존 경구강 타석 제거술군이 $7.0 \pm 2.9 \mathrm{~mm}$ (range, $1 \sim 15 \mathrm{~mm}$ )였고, 설하선 절제 경구강 타 석제거술군, 악하선 절제술군에서 각각 $6.3 \pm 3.7 \mathrm{~mm}$ (range, 2 15 mm), 9.0 $4.5 \mathrm{~mm}$ (range, 3.6 16 mm)로 유의하지 않 았다. 악하선 입구부로부터 타석까지의 평균 거리는 설하선 보존 경구강 타석 제거술군이 $1.4 \pm 1.3 \mathrm{~mm}(\mathrm{range}, 0 \sim 5.0 \mathrm{~mm}$ ) 였고, 설하선 절제 경구강 타석 제거술군, 악하선 절제술군에 서 각각 $1.7 \pm 1.2 \mathrm{~mm}(0 \sim 6.3 \mathrm{~mm}), 1.5 \pm 1.3 \mathrm{~mm}$ (range, 0 5.6 $\mathrm{mm}$ 로 유의하지 않았다. 평균 수술 시간은 설하선 보존 경 구강 타석 제거술군이 39.5 \pm 11.3 (minutes)이었고, 설하선 절 제 경구강 타석 제거술군, 악하선 절제술군에서 각각 $83.2 \pm$ 20.2, 44.0 \pm 7.2 (minutes)로 유의한 차이를 보였다 $(p<0.01)$. 평균 재원 일수는 설하선 보존 경구강 타석 제거술군이 $2.6 \pm$ 0.9 (days)였고, 설하선 절제 경구강 타석 제거술군, 악하선 절 제술군에서 각각 $5.3 \pm 0.5,2.5 \pm 0.3$ (days)으로 유의한 차이를 보였다 $(p=0.021)$. VAS(0 10)은 설하선보존 경구강 타석 제거 술군이 $1.9 \pm 1.0$ 이었고, 설하선절제 경구강 타석 제거술군, 악 하선 절제술군에서 각각 $2.3 \pm 1.9,4.3 \pm 2.8$ 로 유의한 차이를 보였다 $(p=0.033)$. 평균 술 후 외래 추적 관찰 기간은 설하선 보존 경구강 타석 제거술군이 7.4 \pm 5.5 (months; range, 2 23) 이었고, 설하선 절제 경구강 타석 제거술군, 악하선 절제술군 에서 각각 11.6 \pm 4.3 (months; range, 6 24), 18.8 \pm 4.6 (months; range, 12 24)로 유의한 차이를 보이지 않았다(Table 2). 악하 선 절제술군에서 1 명의 환자가 술 후 경부 부종을 보였으나 며칠 내로 자연 소실되었고, 다른 2 명의 환자가 경미한 구강 건조 증상을 호소하였으나 몇 달 이내로 호전되었다. 설하선 보존 경구강 타석 제거술군에서는 4명의 환자가 경미한 악하 선 부위 부종 및 동측 혀 부위 경미한 감각이상 증상을 호소 하였으나, 모든 환자가 3 개월 이내에 회복되는 소견을 보였다. 그 외에 수술 관련 합병증(상처 감염, 감각 이상 혹은 소실, 설신경 기능 변화, meal-time 증후군, 타액선염 발생 여부) 및 영구적인 술 후 합병증이 생긴 환자는 없었다.

\section{고 찰}

최근 들어 악하선 타석의 치료로 타액선을 보존하는 최소 
Table 1. Clinical characteristics of patients

\begin{tabular}{|c|c|c|c|c|c|}
\hline & $\begin{array}{c}\text { Intraoral removal without } \\
\text { sublingual resection }\end{array}$ & $\begin{array}{c}\text { Intraoral removal with } \\
\text { sublingual gland resection }\end{array}$ & $\begin{array}{l}\text { Submandibular } \\
\text { gland resection }\end{array}$ & Total & $p$-value \\
\hline \multicolumn{6}{|l|}{ Sex } \\
\hline Male & 20 & 13 & 7 & 40 & ns \\
\hline Female & 24 & 7 & 8 & 39 & ns \\
\hline \multicolumn{6}{|l|}{ Age } \\
\hline$<50$ & 31 & 9 & 4 & 44 & ns \\
\hline$\geq 50$ & 13 & 11 & 11 & 35 & ns \\
\hline \multicolumn{6}{|l|}{ Side } \\
\hline Right & 19 & 12 & 6 & 37 & ns \\
\hline left & 25 & 8 & 9 & 42 & ns \\
\hline
\end{tabular}

ns: not significant

Table 2. Comparison of surgical outcomes among 3 groups (intraoral removal with sublingual gland resection, intraoral removal without sublingual gland resection, submandibular gland resection)

\begin{tabular}{|c|c|c|c|c|c|c|}
\hline & $\begin{array}{c}\text { Diameter } \\
\text { of stone }(\mathrm{mm})\end{array}$ & $\begin{array}{c}\text { Distances } \\
\text { from the hilum (mm) }\end{array}$ & $\begin{array}{c}\text { Operation time } \\
\text { (minutes) }\end{array}$ & $\begin{array}{l}\text { Hospital stay } \\
\text { (days) }\end{array}$ & $\begin{array}{c}\text { Postoperative } \\
\text { pain (VAS scale) }\end{array}$ & $\begin{array}{c}\text { Follow-up times } \\
\text { (months) }\end{array}$ \\
\hline $\begin{array}{l}\text { Intraoral removal } \\
\text { without sublingual } \\
\text { resection }\end{array}$ & $\begin{array}{c}7.0 \pm 29 \\
\text { (range 1-15) }\end{array}$ & $\begin{array}{c}1.4 \pm 1.3 \\
\text { (range 0-5.0) }\end{array}$ & $39.5 \pm 11.3$ & $2.6 \pm 0.9$ & $1.9 \pm 1.0$ & $\begin{array}{c}7.4 \pm 5.5 \\
\text { (range } 2-23 \text { ) }\end{array}$ \\
\hline $\begin{array}{l}\text { Intraoral removal } \\
\text { with sublingual } \\
\text { gland resection }\end{array}$ & $\begin{array}{c}\quad 6.3 \pm 3.7 \\
\text { (range } 2-15 \text { ) }\end{array}$ & $\begin{array}{l}1.7 \pm 1.2 \\
(0-6.3)\end{array}$ & $83.2 \pm 20.2$ & $5.3 \pm 0.5$ & $2.3 \pm 1.9$ & $\begin{array}{c}11.6 \pm 4.3 \\
\text { (range 6-24) }\end{array}$ \\
\hline $\begin{array}{l}\text { Submandibular } \\
\text { gland resection }\end{array}$ & $\begin{array}{c}9.0 \pm 4.5 \\
\text { (range } 3.6-16)\end{array}$ & $\begin{array}{c}1.5 \pm 1.3 \\
\text { (range } 0-5.6)\end{array}$ & $44.0 \pm 7.2$ & $2.5 \pm 0.3$ & $4.3 \pm 2.8$ & $\begin{array}{c}18.8 \pm 4.6 \\
\text { (range 12-24) }\end{array}$ \\
\hline$p$-value & ns & $\mathrm{ns}$ & $<0.01$ & 0.021 & 0.033 & ns \\
\hline
\end{tabular}

Values are presented as mean \pm standard deviation. VAS: visual analog scale, ns: not significant

침습적인 방법들의 중요성이 더해 가고 있고, 활용 폭도 점점 넓어지고 있다. ${ }^{10-14)}$ 체외 충격파 쇄석술은 타석을 초음파로 확 인하며 전자기장 충격파로 결석을 작게 분쇄하여 제거하는 방법이다. 타액관 내시경은, 내시경으로 타석의 위치를 확인 하고 겸자나 바스켓을 이용하여 제거하는 방법이다. 하지만 타액선 내시경은 비용이 아직까지 비싸다는 점 및 절대적인 시간이 길게 걸린다는 점에서 한계가 있다. ${ }^{15)}$ 이번 연구에서 제시한 설하선 보존 경구강 타석 제거술은 기존의 경구강 타 석 제거 수술법을 변화, 발전시켜 설하선과 소개구부들을 박 리, 보존함으로써, 술 후 하마종(ranula) 발생을 방지하고, 설 신경을 측방으로 보존하며 수술 시야를 확보하여 추가로 설 신경을 박리하거나 확인하지 않아도 되었다. 악하선관을 따 라 근위부로 박리하며 악하선과 악하선 입구부까지 확인이 가능하기 때문에 촉지가 잘 안 되고, 크기가 작은 근위부 타 석들도 제거가 가능하다. 또한 타석 제거 이후 경부측 악하선 부위에서 반복적으로 손가락으로 압력을 가하여 저류되어 있던 점도가 높은 점액이나 타액을 제거하고, 술 전에 확인하 지 못했던 남아 있는 타석이나 다발성 타석들을 확인함으로 써 모든 타석들을 완전히 제거할 수 있었다. 악하선관 성형술
은 시행하지 않았고, 세심한 지혈 후 점막을 1차 봉합함으로 써 수술 시간 및 재원 기간을 단축하고 술 후 불편감을 줄일 수 있었다. 이전에 Roh와 Park은 악하선관 성형술, 악하선 절개 부위 봉합과 증상 재발, 악하선 기능 회복 등과는 상관 이 없음을 보고한 바 있으며, 본원에서도 이와 관련된 술 후 합병증이 없었으며, 이전 Roh와 Park의 보고와 상응하는 결 과를 보였다. ${ }^{16,17)}$ 설하선 보존 경구강 타석 제거술의 장점은 설하선 절제에 따른 타액분비 저하 등의 기능적 손실을 줄일 수 있고, 설하선을 제거하지 않고 수술 범위가 줄어듦에 따 라 술 후 통증 및 불편함과 술 후 발생할 합병증을 줄일 수 있다는 점을 들 수 있다. 본 연구에서는 증례 수가 많지 않아 수술 후 설하선 보존 술식의 장점이 유의하게 나타나지 않았 지만, 추후 더 많은 증례를 통한 연구에서는 이러한 장점이 유의미한 결과를 도출할 수 있을 것으로 생각된다. 실제로 경 구강 타석 제거술군에서는 4명의 환자가 경미한 악하선 부위 부종 및 동측 혀 부위의 경미한 감각 이상 증상을 호소하였 으나, 모든 환자가 3 개월 이내에 회복되는 소견을 보였다. 이는 수술 시야 확보, 박리 시 right angle retractor(Langenback) 에 의해 설신경, 혀 측면 부위가 당겨지고 자극을 받아 발생 
하는 것으로 생각된다. 연구에 따르면 타석 제거 수술 후 대 략 $1.8 \%$ 의 환자에서 하마종이 발생하고 $2 \sim 15 \%$ 의 환자에서 결석이 재발한다고 알려져 있으나 이번 연구에서는 관찰되지 않았다. ${ }^{8)}$ 이번 연구에서 제한점으로 각각의 수술 환자를 무 작위로 배정하지 못하고 과거의 자료와 비교함으로써 편향의 가능성을 가지고 있다는 점과, 악하선 기능에 대한 객관적인 검사 및 결과의 비교가 없다는 점이다. 그러나 수술 방법의 선택에 있어 무작위 배정의 어려움이 있고, 수술자가 한 명으 로 동일하여 시간에 따른 수술 방법의 편향을 최소화하였다 고 생각되며 술 후 구강 건조 증상, meal-time 증후군, 타액 선염 발생 여부 등의 항목들에 대해서도 조사하여 악하선 기 능에 대한 간접적인 평가를 시행한 점에서 부분적인 보완이 되었다고 판단된다.

설하선 보존 경구강 타석 제거술은 간단하면서도 효과적인 수술법으로, 근위부 악하선관 타석의 치료에 있어서 위치, 크기, 촉지 여부 등에 관계없이 적용 가능하며 기존의 방법에 비해 수술 결과도 양호하여 근위부 악하선 타석 치료에 우선 적으로 고려해 볼 수 있겠다.

\section{Acknowledgments}

None.

\section{Author Contribution}

Conceptualization: Keehwan Kwon. Data curation: Minwoo Park. Formal analysis: Keehwan Kwon. Investigation: Geonwoo Kim. Methodology: Geonwoo Kim. Project administration: Jaemoon Sung. Resources: Hwikyeong Jung. Software: Jaesoon Kim. Supervision: Jaemoon Sung. Validation: Minwoo Park. Visualization: Jaesoon Kim. Writing — original draft: Geonwoo Kim. Writing — review \& editing: Keehwan Kwon.

\section{ORCID}

Keehwan Kwon

https://orcid.org/0000-0002-5458-6903

\section{REFERENCES}

1) Harrison JD. Causes, natural history, and incidence of salivary stones and obstructions. Otolaryngol Clin North Am 2009;42(6):
927-47.

2) Rauch S. [Diseases of the salivary glands]. Wien Med Wochenschr 1965;115:261-5.

3) Bodner L. Salivary gland calculi: Diagnostic imaging and surgical management. Compendium 1993;14(5):572, 574-6, 578.

4) Lee DH, Kim SM, Cho JM, Kim MR. A case of fish bone-induced submandibular gland stone. Korean J Otorhinolaryngol-Head Neck Surg 2016;59(2):162-4.

5) Koch M, Iro H, Künzel J, Psychogios G, Bozzato A, Zenk J. Diagnosis and gland-preserving minimally invasive therapy for Wharton's duct stenoses. Laryngoscope 2012;122(3):552-8.

6) McGurk M, Escudier MP, Brown JE. Modern management of salivary calculi. Br J Surg 2005;92(1):107-12.

7) van den Akker HP, Busemann-Sokole E. Submandibular gland function following transoral sialolithectomy. Oral Surg Oral Med Oral Pathol 1983;56(4):351-6.

8) McGurk M, Makdissi J, Brown JE. Intra-oral removal of stones from the hilum of the submandibular gland: Report of technique and morbidity. Int J Oral Maxillofac Surg 2004;33(7):683-6.

9) Eun YG, Chung DH, Kwon KH. Advantages of intraoral removal over submandibular gland resection for proximal submandibular stones: A prospective randomized study. Laryngoscope 2010;120(11): 2189-92.

10) Zenk J, Bozzato A, Winter M, Gottwald F, Iro H. Extracorporeal shock wave lithotripsy of submandibular stones: Evaluation after 10 years. Ann Otol Rhinol Laryngol 2004;113(5):378-83.

11) Nahlieli O, Baruchin AM. Long-term experience with endoscopic diagnosis and treatment of salivary gland inflammatory diseases. Laryngoscope 2000;110(6):988-93.

12) Marchal F, Dulguerov P, Becker M, Barki G, Disant F, Lehmann W. Specificity of parotid sialendoscopy. Laryngoscope 2001;111(2): 264-71.

13) Ottaviani F, Capaccio P, Campi M, Ottaviani A. Extracorporeal electromagnetic shock-wave lithotripsy for salivary gland stones. Laryngoscope 1996;106(6):761-4.

14) Drage NA, Brown JE, Escudier MP, McGurk M. Interventional radiology in the removal of salivary calculi. Radiology 2000;214(1): $139-42$.

15) Park S, Choi JS, Lim JY, Kim YM. Management of sialolithiasis of submandibular gland: Sialendoscopy-assisted intraoral stone removal. Korean J Otorhinolaryngol-Head Neck Surg 2013; 56(4):217.

16) Capaccio $P$, Bottero A, Pompilio M, Ottaviani F. Conservative transoral removal of hilar submandibular salivary calculi. Laryngoscope 2005;115(4):750-2.

17) Roh JL, Park CI. Transoral removal of submandibular hilar stone and sialodochoplasty. Otolaryngol Head Neck Surg 2008;139(2): $235-9$. 